\title{
Seasonal and regional influences on the fatty acid composition of cow's milk fat from Asturias. Spain
}

\author{
By Leocadio Alonso *, Juan Braña and Juan Carlos Bada \\ Instituto de Productos Lácteos de Asturias (CSIC). Carretera de Infiesto s/n. \\ 33300 Villaviciosa, Asturias. Spain. \\ Telephone 34-985892131. Fax 34-985892233. E-mail: lalonso@ipla.csic.es
}

\section{RESUMEN}

Influencias estacionales y regionales en la composición de ácidos grasos de la grasa de leche de vaca de Asturias, España.

Se estudia el efecto de la influencia estacional y de la situación geográfica en la composición de ácidos grasos de la grasa de leche de vaca de Asturias (Norte de España). La mayoría de los ácidos grasos analizados presentaron diferencias $(p<0.05)$ debido a factores estacionales, solo tres ácidos grasos (iC14; iC16 and C18:1) no presentaron diferencias significativas ( $p<$ 0.05 ) ni debido a factores estacionales ni geográficos. Los ácidos grasos de cadena corta, media y larga presentaron diferencias debidas al factor estacional y sólo los ácidos grasos de larga cadena presentaron diferencias con el área geográfica. Sin embargo, sólo los ácidos grasos insaturados mostraron diferencias $(p<$ 0.05 ) debidas a la estación del año y al area geográfica. El coeficiente de correlación obtenido mostró una fuerte relación lineal entre los pares de ácidos grasos C4-C12, C6-C10 y C10-C12.

PALABRAS-CLAVE: : Asturias- Composición de ácidos grasos - Cromatografía gaseosa - España - Grasa de leche de vaca.

\section{SUMMARY}

Seasonal and regional influences on the fatty acid composition of cow's milk fat from Asturias. Spain.

The effect of seasonal and geographical influences on the fatty acid compositions of cow's milk fat from Asturias (northern Spain) was studied. The majority of the fatty acids analysed presented differences $(p<0.05)$ due to the seasonal factor, only three fatty acids (iC14; iC16 and C18:1) did not present significant differences $(p<0.05)$ neither with the seasonal nor with the geographical factor. The short, medium and long chain fatty acids showed differences with the seasonal factor and only the long chain fatty acids presented diferences with the geographical area. However, only the unsaturated fatty acids showed differences $(p<$ 0.05 ) due to both the season of the year and the geographical area. The coefficient of correlation obtained showed a strong linear relationship between the pairs of fatty acids $\mathrm{C} 4-\mathrm{C} 12$, C6-C10 and C10-C12.

KEY-WORDS: Asturias - Cow's milk fat - Fatty acid composition - Gas chromatography - Spain

\section{INTRODUCTION}

Milk fat is formed basically by triglycerides that contain short (C4-C10), medium (C12-C16) and long
(C18-C20) chain fatty acids (Alonso et al. 1987; Alonso, 1993). The long chain fatty acids are originated directly from the fatty acids of the blood plasma, the short chain fatty acids are biosynthesized in the mammary glands and the medium chain are biosynthesized both ways (Alonso et al., 1999). Several factors exist that influence the composition of fatty acids in milk such as the feeding [Bank and Muir, 1981; Black, 1985; Clapperton and Banks, 1985, CSIC, 1978), genetics (Gaunt, 1980; Grummer, 1991; Hargrove et al., 1981) and seasonal factors (Hinrichs et al.,1992 and Juárez et al., 1983; Mahieu, 1978).

Regarding studies that deal with the fatty acid composition of milk from Spain and more concretely from Asturias there is a monographic study (CSIC, 1978) on the fatty acid in milk from Spain. Juárez et al. (1988) and Alonso et al. (1987) provide data concerning the fatty acid composition from a determined area (Cabrales) in Asturias. On an international level there are several more studies on different factors that influence milk fat composition. Storry (1980) carried out research in milk fat composition depending on the feeding of the herd. Banks and Muir (1979) provide information on fatty acid and triglyceride composition of the milk fat depending on the manipulation of the diet in Frisian and Jersey cows. Hinrichs et al. (1974) studied the differences in triglyceride composition of the milk fat in milks obtained during different seasons of the year. Banks and Muir (1981) studied the influence of feeding on the composition of triglycerides. Hargrover et al. (1985) carried out a study on how genetics and environmental factors influence milk composition.

The aim of this study was to analyse the seasonal and geographical evolution of the fatty acid composition of the milk from Asturias (Spain). In order to monitor and improve the quality of milk fat composition in the milk from Asturias, which is the second leading region in milk production from Spain, a comparative study has been made between the different fatty acids analysed with the purpose of 
defining some type of statistical relationship between the different fatty acids studied. The evolution of fatty acids by grouping them according to unsaturation and the length of the carbon chain was studied. Finally, an individual study was carried out on all fatty acids in order to establish the relationships that may exist among them.

\section{MATERIAL AND METHODS}

\subsection{Area selection}

For area selection, the region of Asturias (northern Spain) was divided into three areas: west, center and east. The west includes the representative councils of Navia, Tineo and Vegadeo, the center is represented by the councils of Cudillero, Llanera and Gijón and the east by the councils of Villaviciosa, Colunga and Piloña. The different councils were selected in such a way that the province of Asturias is represented entirely from east to west and so that the size of each area was more or less similar. Selection of the councils in each area was carried out, taking into account its coastal or inland position with the purpose of representing the whole province from the north to south in a similar way for each area.

\subsection{Milk collection}

From January 2001 to December 2001 monthly homogeneus samples from friesian cows feeding on natural pastures were collected from the different councils. Samples were collected from all the cows and mixed according to the milk production of each individual cow to get one representative sample per farm. Five farm samples in each month were then mixed to arrive at one mixed sample per council per month, nine samples were taken per month for analysis, resulting in a total of 108 samples from all over Asturias to be analysed. Samples were collected in flasks $(250 \mathrm{ml})$ and transported at $4^{\circ} \mathrm{C}$.

\subsection{Extration of fat}

The milk was centrifugated at 6000 r.p.m and the separated creams were extracted with petroleum ether and anhydrous sodium sulphate (Alonso, et al. 1999).

\subsection{Cromatography analysis}

The preparation of methyl esters of fatty acids was done according to Martín-Hernández et al. [1988]. The gas chromatography analysis (GLC) was carried out by programme GLC using a Perking-Elmer Autosystem Chromatograph with a 60 m BPX-70 (SGE International pty Ltd Ringwood
Victoria, Australia) capillary column (ID $=0.25 \mathrm{~mm})$ coated with $0.25 \mathrm{~m}$ film thickness (70\% cyanopropyl polysilphenylene siloxane) and flame ionization detector and flow splitter using nitrogen as the carrier gas with a head pressure of 17.0 psi. The initial temperature of $70^{\circ} \mathrm{C}$ was maintained for $3 \mathrm{~min}$, then raised to $175^{\circ} \mathrm{C}$ at a rate of $1.3^{\circ} \mathrm{C} / \mathrm{min}$ for $10 \mathrm{~min}$. The injector and detector temperatures were $250^{\circ} \mathrm{C}$.

\subsection{Stastical analysis}

Statistical analysis was performed using SPSS-PC + 4.0 Software (SPSS Inc., Chicago, IL. USA). Milk was specified as a random effect. The Data of individual fatty acids was subjected to ANOVA for the interaction of two factors in which one is the geographical area and the other is the season of the year. The correlation coefficients have been determined by pairs of fatty acids.

\section{RESULTS AND DISCUSSION}

\subsection{Fatty acid composition}

The grouping of the different councils chosen for this study in three different geographical areas denominated as west, center and east has allowed the results to establish an annual evolution of the fatty acids in milk in function with its geographical area of origin. Table I, gathered the data corresponding to the variation of the different areas and the whole of Asturias as a province. The seasonal evolution of the fatty acids in the different areas was completed by an ANOVA to verify the differences between the different means. ANOVA was established in two ways: the season of the year and the geographical area. The application of this analysis allowed the separation of three possible sources of variation: variation between seasons, variation between geographical areas and aleatorial variation due to experimental error. Considering variations due to the season and the geographical area as significant the estimation of the variances of the areas and seasons was then compared to the variance estimated with the aleatory error by means of the t-test. All the fatty acids of this study have been subjected to this test.

All of the fatty acids studied showed significant results $(p<0.05)$ due to the seasonal effect except the $\mathrm{iC}_{14}, \mathrm{iC}_{15}, \mathrm{iC}_{16}$ and the $\mathrm{C}_{18: 1}$. On the other hand, the differences with respect to the geographical areas have been found inferior to those relating to the seasons with a significance $(p<0.05)$ for the fatty acids $\mathrm{C}_{4}, \mathrm{C}_{6}, \mathrm{C}_{8}, \mathrm{iC}_{15}, \mathrm{C}_{16}, \mathrm{iC}_{17}, \mathrm{C}_{17: 1}, \mathrm{C}_{18: 0}, \mathrm{C}_{18: 2}, \mathrm{C}_{18: 3}$ and CLA (conjugated linoleic acid) and $(p<0.01)$ for the fatty acids $\mathrm{C}_{4}, \mathrm{C}_{14}, \mathrm{C}_{16}, \mathrm{iC}_{17}, \mathrm{C}_{17}, \mathrm{C}_{18: 0}, \mathrm{C}_{18: 2}, \mathrm{C}_{18: 3}$ and CLA. Only the fatty acids $\mathrm{iC}_{14}, \mathrm{iC}_{16}$ and $\mathrm{C}_{18: 1}$ did not present any significant result neither with the 
Table I

Seasonal fatty acids composition (\% total fatty acids) of cow's milk fat from west, centre, east of Asturias and the whole Asturias as province (\%)

\begin{tabular}{|c|c|c|c|c|c|c|c|c|c|c|c|c|c|c|c|}
\hline \multirow{2}{*}{$\begin{array}{l}\text { Fatty } \\
\text { acid } \\
\end{array}$} & \multicolumn{4}{|c|}{ West } & \multicolumn{4}{|c|}{ Centre } & \multicolumn{4}{|c|}{ East } & \multirow[b]{2}{*}{ Asturias } & \multicolumn{2}{|c|}{ Significance } \\
\hline & WI & SP & SU & $\mathrm{AU}$ & WI & SP & SU & $\mathrm{AU}$ & WI & SP & SU & $\mathrm{AU}$ & & Season & Areas \\
\hline $\mathrm{C}_{4: 0}$ & 4.42 & 4.04 & 4.05 & 4.48 & 4.44 & 4.15 & 4.11 & 4.52 & 4.41 & 3.95 & 3.88 & 4.39 & 4.29 & $* *$ & $* *$ \\
\hline $\mathrm{C}_{6: 0}$ & 2.58 & 2.32 & 2.33 & 2.57 & 2.53 & 2.35 & 2.33 & 2.58 & 2.59 & 2.29 & 2.22 & 2.60 & 2.47 & $* *$ & $*$ \\
\hline $\mathrm{C}_{8: 0}$ & 1.40 & 1.30 & 1.32 & 1.41 & 1.35 & 1.35 & 1.44 & 1.36 & 1.42 & 1.29 & 1.19 & 1.43 & 1.38 & $* *$ & NS \\
\hline $\mathrm{C}_{10: 0}$ & 2.91 & 2.60 & 2.66 & 2.93 & 2.73 & 2.64 & 2.64 & 2.76 & 2.99 & 2.46 & 2.36 & 3.01 & 2.76 & $* *$ & NS \\
\hline $\mathrm{C}_{10: 1}$ & 0.28 & 0.27 & 0.30 & 0.28 & 0.32 & 0.28 & 0.29 & 0.31 & 0.31 & 0.28 & 0.26 & 0.33 & 0.30 & $* *$ & NS \\
\hline $\mathrm{C}_{12: 0}$ & 3.33 & 2.95 & 3.01 & 3.32 & 3.13 & 2.98 & 3.01 & 3.14 & 3.28 & 2.81 & 2.73 & 3.34 & 3.13 & $* *$ & NS \\
\hline iso- $\mathrm{C}_{14}$ & 0.14 & 0.26 & 0.24 & 0.15 & 0.18 & 0.21 & 0.22 & 0.18 & 0.19 & 0.20 & 0.23 & 0.21 & 0.20 & NS & NS \\
\hline $\mathrm{C}_{14: 0}$ & 10.91 & 10.38 & 10.29 & 10.89 & 11.19 & 10.61 & 10.70 & 11.07 & 11.01 & 10.54 & 10.50 & 11.34 & 10.93 & $* *$ & $* *$ \\
\hline $\mathrm{C}_{14: 1}$ & 1.12 & 1.04 & 1.13 & 1.10 & 1.25 & 1.03 & 0.97 & 1.23 & 1.13 & 1.02 & 1.04 & 1.19 & 1.11 & $* *$ & NS \\
\hline iso- $\mathrm{C}_{15}$ & 0.55 & 0.61 & 0.65 & 0.54 & 0.65 & 0.63 & 0.57 & 0.63 & 0.59 & 0.57 & 0.55 & 0.60 & 0.61 & NS & $*$ \\
\hline $\mathrm{C}_{15: 0}$ & 1.19 & 1.15 & 1.18 & 1.19 & 1.24 & 1.10 & 1.09 & 1.24 & 1.22 & 1.09 & 1.09 & 1.25 & 1.20 & $* *$ & NS \\
\hline iso- $\mathrm{C}_{16}$ & 0.60 & 0.59 & 0.60 & 0.54 & 0.52 & 0.59 & 0.59 & 0.59 & 0.51 & 0.53 & 0.49 & 0.64 & 0.58 & NS & NS \\
\hline $\mathrm{C}_{16: 0}$ & 30.11 & 28.07 & 28.12 & 30.23 & 28.21 & 27.62 & 27.57 & 28.12 & 25.53 & 27.01 & 26.54 & 29.12 & 27.92 & $* *$ & $* *$ \\
\hline$C_{16: 1}$ & 2.00 & 2.12 & 2.16 & 2.01 & 1.98 & 2.22 & 2.19 & 1.93 & 1.93 & 2.11 & 2.18 & 28.49 & 2.10 & $* *$ & NS \\
\hline iso- $\mathrm{C}_{17}$ & 0.53 & 0.59 & 0.60 & 0.55 & 0.59 & 0.64 & 0.64 & 0.60 & 0.59 & 0.62 & 0.61 & 0.61 & 0.61 & $* *$ & $* *$ \\
\hline $\mathrm{C}_{17: 0}$ & 0.56 & 0.74 & 0.73 & 0.59 & 0.62 & 0.90 & 0.92 & 0.60 & 0.60 & 0.97 & 1.00 & 0.62 & 0.76 & $* *$ & $* *$ \\
\hline$C_{17: 1}$ & 0.33 & 0.75 & 0.72 & 0.35 & 0.36 & 0.66 & 0.61 & 0.36 & 0.31 & 0.97 & 1.16 & 0.33 & 0.59 & $* *$ & $*$ \\
\hline $\mathrm{C}_{18: 0}$ & 10.69 & 11.94 & 11.71 & 10.74 & 10.94 & 11.97 & 11.86 & 11.01 & 10.98 & 12.73 & 13.00 & 10.78 & 11.71 & $* *$ & $* *$ \\
\hline $\mathrm{C}_{18: 1}$ & 23.02 & 24.53 & 24.49 & 22.79 & 23.93 & 24.22 & 24.40 & 23.81 & 23.96 & 24.63 & 24.82 & 22.67 & 24.38 & NS & NS \\
\hline $\mathrm{C}_{18: 2}$ & 1.86 & 1.70 & 1.75 & 1.79 & 1.67 & 1.49 & 1.47 & 1.62 & 1.60 & 1.43 & 1.50 & 1.65 & 1.66 & $* *$ & $* *$ \\
\hline $\mathrm{C}_{18: 3}$ & 0.40 & 0.49 & 0.49 & 0.39 & 0.53 & 0.66 & 0.69 & 0.53 & 0.51 & 060 & 0.62 & 0.52 & 0.55 & $* *$ & $* *$ \\
\hline CLA $^{2}$ & 0.59 & 0.71 & 0.68 & 0.63 & 0.68 & 0.79 & 0.73 & 0.62 & 0.67 & 0.78 & 0.70 & 0.63 & 0.68 & $* *$ & $* *$ \\
\hline $\mathrm{C}_{20: 0}$ & 0.28 & 0.25 & 0.20 & 0.33 & 0.30 & 0.21 & 0.22 & 0.45 & 0.30 & 0.21 & 0.20 & 0.30 & 0.28 & $* *$ & NS \\
\hline
\end{tabular}

${ }^{1}$ Means of duplicate analysis; ${ }^{2}$ Conjugated linoleic acid (CLA); ${ }^{3}$ No significance (NS); * $\mathrm{P} \leq 0.05 ; * * \mathrm{P} \leq 0.01$

WI: winter; SP: spring; SU: summer; AU: autumn.

season nor with the geographical areas with respect to the factors studied and only the $\mathrm{iC}_{15}$ showed significant results with the two effects mentioned. All of this data is in accordance with the results found by Martinez-Castro et al. (1979) in a study of the composition of milk fat in Spain. However, these authors found a higher significance in the geographical areas due to the greater climatological differences than in relation to this work in which the areas chosen showed more uniform characteristics.

\subsection{The Composition of fatty acids classified by nutritional categories}

Table II summarises the avarage values of the different fatty acids classified in three nutritional categories according to the carbon chain: short $\left(\mathrm{C}_{4: 0}-\mathrm{C}_{10: 1}\right)$, medium $\left(\mathrm{C}_{12: 0}-\mathrm{C}_{17: 0}\right)$ and long $\left(\mathrm{C}_{18: 0}-\mathrm{C}_{20: 0}\right)$ along with the degree of unsaturation (saturated and unsaturated fatty acids) which also includes the data corresponding to Asturias as a province. In relation to this classication of the fatty acids, a comparative study by ANOVA has been made of the evolution experimented by those fatty acids with respect to the geographical area and the season of the year.

The low effect of interference between season and geographical area stands out as significant $(p<0.05)$ for the medium chain length. The seasonal effect showed significance $(p<0.05)$ regardless of the length of the chain. However, the effect of geographical area which presents the greatest variation regarding the length of the carbon chain and the short chain fatty acids did not present any significance with the geographical area.

The long chain fatty acid presented the opposite effect because it showed significance for the two levels studied and the medium chain fatty acid presented significance for $p<0.05$ level only. It is important to point out the opposite effect that the experiment revealed on the long chain fatty acids in relation with the short and medium chains considering the season of the year. At the same time, the short and medium fatty acids decreased in spring and summer, while the long chain fatty acids increased in these two seasons. Black (1985) and Thomas and Rowney (1996) confirm the variation in the chain length of fatty acids in relation to the seasons and the geographical areas in a study on Australian milks. These differences are remarkable and are in accordance with the results obtained in this work. Parodi (1974) has pointed out the existence of variation within an area which is greater in dry areas than in wet areas. In our study the choice of two coastal areas and one interior resulted in similar climates which did not permit us to find the differences found by Parodi (1974). Higher values for saturated fatty acids were recorded in winter and autumn, while the unsaturated fatty acids showed an 
Table II

Seasonal fatty acids composition (\% total fatty acids) by nutritional categories of cow's milk fat from west, centre, east and the whole Asturias as province

\begin{tabular}{|c|c|c|c|c|c|c|c|c|c|c|c|c|c|c|c|}
\hline \multirow{2}{*}{$\begin{array}{l}\text { Fatty }{ }^{1} \\
\text { acid }(\%)\end{array}$} & \multicolumn{4}{|c|}{ West } & \multicolumn{4}{|c|}{ Centre } & \multicolumn{4}{|c|}{ East } & \multirow[b]{2}{*}{ Asturias } & \multicolumn{2}{|c|}{ Significance } \\
\hline & WI & SP & SU & $\mathrm{AU}$ & WI & SP & SU & $\mathrm{AU}$ & WI & SP & SU & $\mathrm{AU}$ & & Season & Areas \\
\hline SCFA & 11.69 & 10.13 & 10.74 & 11.69 & 11.36 & 10.73 & 10.82 & 11.53 & 11.73 & 10.26 & 9.90 & 11.74 & 11.54 & $*$ & NS \\
\hline MCFA & 49.99 & 47.42 & 47.58 & 50.05 & 48.68 & 47.62 & 47.28 & 48.49 & 48.41 & 46.35 & 45.95 & 49.75 & 45.88 & $*$ & $* *$ \\
\hline LCFA & 38.32 & 42.05 & 41.68 & 38.26 & 39.96 & 41.65 & 41.90 & 39.98 & 39.86 & 43.39 & 38.51 & 39.74 & 42.58 & $* *$ & $* *$ \\
\hline Saturated & 70.33 & 68.04 & 67.92 & 70.54 & 68.95 & 68.47 & 68.29 & 69.21 & 69.22 & 67.71 & 67.17 & 69.80 & 68.81 & $*$ & NS \\
\hline Unsaturated & 29.67 & 31.96 & 32.08 & 29.46 & 31.05 & 31.53 & 31.71 & 30.79 & 30.78 & 32.29 & 32.83 & 30.18 & 31.18 & $*$ & $*$ \\
\hline
\end{tabular}

${ }^{1}$ Means of duplicate analysis; No significance (NS); * $\mathrm{P} \leq 0.05 ; * * \mathrm{P} \leq 0.01$.

SCFA: Short chain fatty acids $\left(\mathrm{C}_{4: 0}-\mathrm{C}_{10: 1}\right)$; MCFA: Medium chain fatty acids $\left(\mathrm{C}_{12: 0} \mathrm{C}_{17: 0}\right)$; LCFA: Long chain fatty acids $\left(\mathrm{C}_{18: 0} \mathrm{C}_{20: 0}\right)$

WI: winter; SP: spring; SU: summer; AU: autumn.

inverse evolution but in a lesser magnitude. Perhaps these values are different from those found by Tomas and Rowney (1996) because the effect of the climate conditions is greater in the fatty acids than that presented by the degree of unsaturation or the length of carbon chain. Only the unsaturated fatty acids presented significance $(p<0.05)$ for all effects studied. It can be assumed that for a level of significance $(p<0.01)$ no fatty acid presented significance whether with geographical area or with the season of the year nor with both interferences. It also stands out that the low variation observed for the saturated fatty acids only presented significance $(p<0.05)$ for the season of the year.

\subsection{Relations between fatty acids}

A study has been carried out to verify the relationships between the different fatty acids analysed by comparing the two by means of the data obtained for each one of them in a global way and taking the data of Asturias as a province. This coefficient of correlation gives a possible linear estimation which could exist between the different fatty acids and if this correlation is positive or negative. The high value obtained for the coefficient of correlation for the pairs of fatty acids $\mathrm{C}_{4}-\mathrm{C}_{12} ; \mathrm{C}_{6}-\mathrm{C}_{10}$ and $\mathrm{C}_{10}-\mathrm{C}_{12}$ stands out an this has permitted us to establish a dependence almost totally linear between these pairs of fatty acids. The pairs $\mathrm{C}_{4}-\mathrm{C}_{6} ; \mathrm{C}_{4}-\mathrm{C}_{10}$; $\mathrm{C}_{6}-\mathrm{C}_{12}, \mathrm{C}_{17}-\mathrm{C}_{17: 1}$ and $\mathrm{C}_{17: 1}-\mathrm{C}_{18}$ also presented a high correlation which is the same as the pair $\mathrm{C}_{4}-\mathrm{C}_{18}$ but those fatty acids, in this case, have shown a negative coefficient of correlation. The predominance of a negative correlation also stands out, when the pairs are formed by a short chain fatty acid with a long chain fatty acid; however, positive correlations exist when the relations of fatty acids are of similar chain length. It is also worthy to note that the unsaturated fatty acids present a lower coefficient of correlation between themselves than the saturated fatty acids, with the exception of the fatty acid $\mathrm{C}_{17: 1}$. The coefficients of correlation obtained in this work are somewhat higher than those obtained by Martinez-Castro et al. (1979) in a study of the fatty acid composition of the milk fat in Spain. This is understandable because in this case there are more factors which influence the fatty acid compositions.

The value obtained for the coefficient of correlation $\mathrm{C}_{4}$ and $\mathrm{C}_{12}$ permitted a development of the analysis of linear regression for this case obtaining a line with a coefficient of determination $(r=0.995)$ and a equation of the type:

$$
Y=1.244 X+0.406
$$

which permitted an accurate value for the fatty acid C4 (Y) from the C12 (X).In the same way a multiple linear estimation for determining the concentration of C4 from the C10 and C12 obtaining a equation $(r=0.991)$ of the type:

$$
Y=1.387 X_{1}-0.146 X_{2}+0.364
$$

where $Y$ represents the value for the concentration of $\mathrm{C}_{4}$ and $\mathrm{X}_{1}$ and $\mathrm{X}_{2}$ represents the values for the concentrations for $\mathrm{C}_{10}$ and $\mathrm{C}_{12}$ respectively. The values obtained in this study have accurately shown that the determination of butyric acid from other fatty acids is easier to determine due to the fact that it is less volatile.

\section{CONCLUSIONS}

The majority of the fatty acids analysed presented significant variations due to the seasonal factor; the significant differences due to the influence of the geographical area have been presented by a fewer number of fatty acids, only three fatty acids $\left(\mathrm{iC}_{14}, \mathrm{iC}_{16}\right.$ and $\left.\mathrm{C}_{18: 1}\right)$ from all fatty acids analysed represented any difference neither with the season nor with the geographical area. The concentration of short and medium fatty acids decreased during the seasons of spring and summer while the long chain fatty acids increased during these seasons. The short, medium and long fatty acids presented differences due to the 
seasonal factor. However, only the long chain fatty acids showed differences within the geographical area. The saturated fatty acids have shown the highest concentrations in winter and autumn while the unsaturated fatty acids have shown the highest concentrations in spring and summer. Only the unsaturated fatty acids presented differences $(p<0.05)$ with the season of the year and with the geographical area. The pairs of fatty acids $\mathrm{C}_{4}-\mathrm{C}_{12}$, $\mathrm{C}_{6}-\mathrm{C}_{10}$ and $\mathrm{C}_{10}-\mathrm{C}_{12}$ have shown a strong lineal relation, the negative coefficient correlation predominate when the pairs of fatty acids are formed by a short fatty acid and a long fatty acid.

\section{ACKNOWLEDMENTS}

The authors acknowledge financial support from FICYT, Principado de Asturias, Spain and the Laboratorio Interprofesional Lácteo de Asturias (LILA) with special memory to Cesar Garcia.

\section{BIBLIOGRAPHY}

1. Alonso, L., Juárez, M., Ramos, R. and Martín-Alvarez, P.J. (1987) Overall composition, nitrogen fractions and fat characteristics of Cabrales cheese during ripening. Z. Lebensm. Unters Forsch., 1, 481-486.

2. Alonso, L. (1993) Capillary gas chromatography of some triglycerides in cheese using programmed temperature injection. Chromatographia, 21, 37-40.

3. Alonso, L., Fontecha, J., Lozada, L., Fraga, M.J. and Juárez. M. (1999) Fatty acid composition of goat milk fat. Major, branched-chain and trans fatty acids. J. Dairy Sci. 5, 878-884.

4. Banks, W. and Muir, D.D. (1981) The compositional quality of milk. Hannah Research Institute Report.

5. Black, R.G. (1985) Fatty acid composition of Victorian milk fat. The Dairy Technologist. Gilbert Chandlerl Institute of Dairy Technology 48-52.

6. Clapperton, J.L. and Banks, W. (1985) Factors affecting the yield of milk and its constituents, particularly fatty acids, when dairy cows consume diets containing added fat. J. Sci. Food Agric. 36, 1205-1212.

7. CSIC. (1978). Estudio sobre la composición de la leche de vaca en España. Instituto de Productos Lácteos, Arganda del Rey Madrid.

8. Gaunt, S.N. (1980) Genetic variation in the yields and contents of milk constituents. F.I.L. Doc. 125, 73-89. Brussels.

9. Grummer. R.R. (1991) Effect of feed on the composition of milk fat. J. Dairy Sci. 74, 3244- 3256

10. Hargrove,G.L., Mbah, D.A and Rosemberger, J.L. (1981) Genetic and environmental influences on milk and milk component production. J. Dairy. Sci. 64, 1593-1597.

11. Hinrichs, J., Heineman, U. And Kessler, H.G. (1992) Differences in the composition of triglycerides in summer and winter milk fat. Milchwissenschaft 47, 495-498.

12. Juárez, M., Alonso, L. and Ramos, M. (1983) Lipolisis y proteolisis del queso de Cabrales durante la maduración. Rev. Agroquimia Tecnol. Aliment. 23, $541-551$

13. Kefford, B., Christian. M.P., Sutherland, B.J., Mayes, J.J and Grainger. C. (1995) Seasonal influences on Cheddar cheese manufacture: influence of diet quality and stage of lactation. Aust. J. Dairy Technol. 47, 105-107.

14. Mahieu. H. (1978) Incidences sur la composition du lait. I.T.E.B Paris.

15. Martín-Hernández, M.C., Alonso, L., Juárez, M. and Fontecha, J. (1988) Gas chromatographic method for determining free fatty acids in cheese. Chromatographia 25, 87-90.

16. Martínez-Castro, I., Juárez, M. and Martín-Alvarez. P.J. The composition of fatty acids of milk fat in Spain. Milchwissenschaft 34, 207-210.

17. Parodi. P.W. (1974) Variation in the fatty acid composition of milk fat: effect of stage of lactation. Aust. J. Dairy Tech. 29,145-148.

18. Rowney, M. and Christian, M. (1996) Effect of cow diet and stage of lactation on the composition of milk fat for cheese manufacture. The Australian Journal Dairy Thechnology 51, 118-122.

19. Sharma, A.K., Wilcox C.J., Bachman, K.C. and Collier, R.J. (1979) Efectos climatológicos y fisiológicos sobre el rendimiento y la composición de la leche de vaca. Compendio VII. Reunión Latinoamericana de Producción Animal 143-158. Argentina.

20. Sharma. A.K. (1980) Climatological, environmental, genetic and matematical aspects of milk composition and yield. Disert. Abstr. Int. B 40, 122-127.

21. Storry. (1972) J.E Milk fat: its synthesis and composition in relation to the nutrition of the dairy cow. J. Soc. Dairy Technol. 25, 40-46.

22. Storry, J.E. (1980) Influence of nutritional factors on the yield and content of milk fat: non-protected fat in the diet. Page 88 in IDF Bull. 125, Int. Dairy Fed. Brussels.

23. Thomas, L. and Rowney, M. (1996) Australian milk fat survey fatty acid composition. Aust. J. Dairy Technol. $\mathbf{5 1}, 112-114$.

24. Wilcox, C.J., Gaunt, S.N. and Farthing. B.R. (1971). Genetic interrelationships of milk composition and yield. South. Coop. Ser. Bull. 155.

Recibido: Febrero 2003 Aceptado: Septiembre 2003 